\title{
MATING PREFERENCES AND SEXUAL SELECTION IN THE ARCTIC SKUA
}

\section{ESTIMATION OF PARAMETERS AND TESTS OF HETEROGENEITY}

\author{
P. O'DONALD and J. W. F. DAVIS \\ Department of Genetics, University of Cambridge, Downing Street, Cambridge CB2 3EH, England
}

Received 25.x.76

\begin{abstract}
SUMMARY
Data of the breeding of pale, intermediate and dark phenotypes in a population of Arctic Skuas are analysed and fitted to models of sexual selection. In the model which fits best, groups of females become ready to breed during successive intervals in the breeding season. Females with preferences mate first, some preferring the dark males and others the intermediates; the remaining females then mate at random. At maximum likelihood, 14 per cent of females prefer dark males and 29 per cent prefer intermediate males. The likelihood surfaces of the models are illustrated with respect to the parameters of the mating preferences. An analysis of $\chi^{2}$ shows that after fitting the mating preferences and allowing for variation in breeding times, no heterogeneity is left in the data. Observations of assortative mating and the behaviour during pairing also support the model. The female preferences can be explained as the result of different thresholds in the females' responses. These may have evolved in earlier, warmer periods when dark and intermediate phenotypes must have had an overall advantage.
\end{abstract}

\section{INTRODUCTION}

In the first paper of this series, O'Donald, Wedd and Davis (1974) analysed data on the fledging success of pairs of Arctic Skuas according to their phenotype, sex and breeding date. When males are mating for the first time, or when they are changing their mates, the dark-plumaged phenotypes breed on average earlier in the breeding season than the intermediates, who breed before the pales. Female mating preferences for dark and intermediate males may explain these differences in breeding times. O'Donald, Wedd and Davis fitted models of mating preferences to the data of the breeding times and thus estimated the proportions of females mating preferentially. O'Donald (1976a) fitted a series of models to the data by maximum likelihood. Davis and O'Donald (1976) also found that intermediates mate assortatively with each other. From the numbers of the different matings between the phenotypes, they estimated the preference of intermediate females for intermediate males. This agreed closely with the overall preference for intermediate males estimated from the breeding times. The coefficients of sexual selection can be estimated from the fledging success of pairs breeding at different times.

The data which were used in these calculations were collected from 1948 to 1962 during an intensive study of a colony of Arctic Skuas on Fair Isle. K. Williamson, Warden of the Fair Isle Bird Observatory, began the study and it was later continued by P. E. Davis, who followed Williamson as Warden, and P. O'Donald. From 1973, J. W. F. Davis and P. O’Donald have returned to study the Fair Isle Arctic Skuas. These had increased 
from 71 pairs in 1962 to 106 pairs in 1973 and continued to increase to 116 pairs in 1974 and to 137 pairs in 1975 . More data have now becn obtained for the estimation of the mating preferences. In this paper we analyse all the data, estimate the mating preferences and test the heterogeneity between the two periods 1948-62 and 1973-75.

\section{The data of the ARGTic SKUA}

Sexual selection takes place among the males when new pairs are being formed. Table 1 shows the distributions of breeding dates of males in new pairs for the years 1948-62 and 1973-75. The breeding season has been

TABLE 1

Distributions of breeding dates of dark, intermediate and pale males in new pairs

\begin{tabular}{|c|c|c|c|c|c|c|c|c|c|}
\hline \multirow{2}{*}{$\begin{array}{l}\text { Breeding dates } \\
\text { in weekly } \\
\text { intervals }\end{array}$} & \multicolumn{3}{|c|}{ Data for $1948-62$} & \multicolumn{3}{|c|}{ Data for $1973-74$} & \multicolumn{3}{|c|}{ Combined data } \\
\hline & Darks & Inters & Pales & Darks & Inters & Pales & Darks & Inters & Pales \\
\hline 10-16 June & 1 & 2 & 1 & 1 & 0 & 0 & 2 & 2 & 1 \\
\hline 17-23 June & 8 & 24 & 3 & 1 & 9 & 1 & 9 & 33 & 4 \\
\hline 24-30 June & 16 & 19 & 6 & 5 & 27 & 3 & 21 & 46 & 9 \\
\hline 1-7 July & 10 & 24 & 6 & 5 & 9 & 7 & 15 & 33 & 13 \\
\hline 8-14 July & 3 & 15 & 5 & 2 & 6 & 7 & 5 & 21 & 12 \\
\hline 15-21 July & 1 & 2 & 5 & 2 & 5 & 0 & 3 & 7 & 5 \\
\hline Totals of birds & 39 & 86 & 26 & 16 & 56 & 18 & 55 & 142 & 44 \\
\hline
\end{tabular}

divided into the same arbitrary weekly periods that O'Donald, Wedd and Davis used for fitting the models of mating preferences. Arctic Skuas normally lay two eggs, but late in the breeding season they often lay only one. The breeding dates are measured by the hatching date of the first chick. The differences in the distributions of breeding dates are observed only when the males have formed a new pair: these differences disappear if the male remains with the same female in later ycars; such differences are not observed between the phenotypes of females. At any time in the breeding season a dark or intermediate male is more likely to find a mate than a pale male. We can explain this by assuming that the females mate preferentially with dark and intermediate males. Different behavioural mechanisms give rise to different models of mating preferences: the models and their interpretation in behavioural terms have already been described in detail (O'Donald, 1976a, 1976b).

The combined data show that in new pairs, the pale males breed very significantly later than the others. Table 2 gives an analysis of variance of the individual (ungrouped) breeding dates of dark, intermediate and pale males. If $\bar{x}_{D}, \bar{x}_{I}$ and $\bar{x}_{P}$ are their mean breeding dates, then

$$
\begin{aligned}
& \bar{x}_{D}=29 \cdot 218 \\
& \bar{x}_{I}=30 \cdot 049 \\
& \bar{x}_{P}=34 \cdot 091 .
\end{aligned}
$$

\section{Maximum likelihood estimates of parameters}

Since O'Donald $(1976 a, 1976 b)$ has already described the details of the models, we shall only describe them here in outline. In some models, 
TABLE 2

Analysis of variance of breeding dates of males in new pairs

Component of variation

Comparison between pale and non-pale

Comparison between intermediate and dark

Comparison between pale intermediate and dark

Within phenotypes

Total

$\begin{array}{crc}\begin{array}{c}\text { Degrees of } \\ \text { freedom }\end{array} & \begin{array}{r}\text { Sum of } \\ \text { squares }\end{array} & \begin{array}{c}\text { Mean } \\ \text { square }\end{array} \\ 1 & 656.90 & 656 \cdot 90 * * \\ 1 & 27.39 & 27 \cdot 39 \\ & & \\ 2 & 684.29 & 342 \cdot 14 * \\ 238 & 14659 \cdot 67 & 61.59 \\ 240 & 15343.96 & \end{array}$

Significant at a probability of about 0.001.

* Significant at a probability of about 0.006 .

matings occur among groups of males and females during successive intervals in the breeding season; the preferential matings either precede ( $\mathrm{P}$ models) or follow ( $\mathrm{R}$ models) the random matings. In other models, preferential and random matings occur simultaneously ( $\mathrm{S}$ models) as females arrive one after the other to mate. The females may prefer intermediate and dark males indiscriminately (model 1); they may prefer darks before intermediates and intermediates before pales (model 2); some females may only prefer darks, while others prefer darks and intermediates indiscriminately (model 3); some may only prefer darks, while others only prefer intermediates (model 4).

The preferences are measured by the proportions of the females with preferences: $\alpha$ is the preference for dark males; $\beta$ is the preference for intermediates alone, or for both dark and intermediate males. Thus in model l, $\beta$ measures the preference for darks and intermediates; in model 2, $\alpha$ measures the preference for darks over intermediates or intermediates over pales; in models 3 and $4, \alpha$ measures the preference for darks; $\beta$ measures the preference for both intermediates and darks in model 3, or the preference for intermediates alone in model 4 .

Trial and error has been used to find the maximum likelihood estimates of these parameters. Starting with arbitrary values of the parameters, random perturbations of their values are introduced and the likelihoods computed. After 50 trials, the values giving the highest likelihood are chosen. Smaller random perturbations are then introduced into the new values. Further new values giving a higher likelihood are chosen after another 50 trials. This process is repeated with smaller and smaller random perturbations: the estimates perform a random walk up the likelihood surface taking smaller and smaller steps until the maximum is reached. In calculating the likelihoods, the numbers breeding in the first week have been lumped together with those breeding in the second week. This was done to avoid having very small expected numbers. For each set of values of parameters, the expected numbers, $m_{i}$, in each class are thus calculated and hence the log likelihood

$$
\log _{e} L=\sum_{i} a_{i} \log _{e} m_{i}
$$

where $a_{i}$ is the observed number in the $i$ th class. Table 3 shows the estimates of the parameters at maximum likelihood. 
TABLE 3

\begin{tabular}{|c|c|c|c|}
\hline \multirow[b]{2}{*}{ Model } & \multicolumn{2}{|c|}{$\begin{array}{c}\text { Parameters of female } \\
\text { preference }\end{array}$} & \multirow[b]{2}{*}{$\begin{array}{l}\text { Log likelihood } \\
\quad \text { (to base } e \text { ) }\end{array}$} \\
\hline & $\alpha$ & $\beta$ & \\
\hline $\begin{array}{l}1 P \\
1 \mathrm{R} \\
1 \mathrm{~S}\end{array}$ & - & $\begin{array}{l}0 \cdot 425 \\
0 \cdot 246 \\
0 \cdot 337\end{array}$ & $\begin{array}{l}-336.509 \\
-337.695 \\
-337.004\end{array}$ \\
\hline $\begin{array}{l}2 P \\
2 R\end{array}$ & $\begin{array}{l}0.065 \\
0.043\end{array}$ & - & $\begin{array}{l}-340 \cdot 441 \\
-340 \cdot 191\end{array}$ \\
\hline $\begin{array}{l}3 \mathrm{P} \\
3 \mathrm{R} \\
3 \mathrm{~S}\end{array}$ & $\begin{array}{l}0.024 \\
0.023 \\
0.023\end{array}$ & $\begin{array}{l}0.402 \\
0 \cdot 221 \\
0.313\end{array}$ & $\begin{array}{l}-336.429 \\
-337 \cdot 535 \\
-336.863\end{array}$ \\
\hline $\begin{array}{l}4 P \\
4 R \\
4 S\end{array}$ & $\begin{array}{l}0.137 \\
0.084 \\
0.111\end{array}$ & $\begin{array}{l}0 \cdot 292 \\
0 \cdot 165 \\
0.228\end{array}$ & $\begin{array}{l}-336 \cdot 302 \\
-337 \cdot 420 \\
-336 \cdot 765\end{array}$ \\
\hline
\end{tabular}

In the $\mathrm{P}$ and $\mathrm{R}$ models, mating takes place among groups of individuals. The size of the group can be varied. We have used the groups breeding in each weekly interval as given in table 1. The groups can be reduced to the numbers mating each day: the expected frequencies of matings are then lumped together again into the weekly intervals for the calculation of $\log$ likelihoods. The $\mathrm{P}$ and $\mathrm{R}$ models converge very closely towards the $\mathrm{S}$ models as the size of group is reduced: preferential and random matings are then occurring more or less simultaneously.

Models $2 \mathrm{P}$ and $2 \mathrm{R}$ are excluded: they give $\log$ likelihoods more than 3 units below the log likelihood of the most likely model-model 4P. Edwards (1972) calls this difference of log likelihoods the "support" for the hypothesis. Two units of support represent approximately 95 per cent confidence limits of a normally distributed variable. The $\mathrm{R}$ models are approximately $1 \cdot 1$ units of support below the $\mathrm{P}$ models. This does not represent a statistically significant increase of support for the P models: the data do not in fact discriminate between models 1,3 or 4 , even though the $\mathrm{P}$ models are the most strongly supported. The total proportion of females with a preference is about the same within each of the $\mathrm{P}, \mathrm{R}$ and $\mathrm{S}$ models. Model 1 , in which the females prefer both intermediate and dark males, is sufficient to explain the present observations. The preferential matings probably take place before the random matings. This suggests that the females with the preferences may be responding at a lower threshold to the darker males, thus mating before the others (O'Donald, 1976b).

The contingency $\chi^{2}$ can be calculated before and after the fitting of the parameters. In the combined data shown in table 1 , the data of the first 2 and last 2 weeks were lumped together to give reasonably large expected numbers for the calculation of $\chi^{2}$. Before fitting the mating preferences, we find that for six degrees of freedom

$$
\chi_{6}^{2}=13 \cdot 263 \text {. }
$$

After fitting the two parameters of model $3 \mathrm{P}$, we find that for four degrees of freedom

$$
\chi_{4}^{2}=2 \cdot 316
$$

and after fitting model $4 \mathrm{P}$

$$
\chi_{4}^{2}=2 \cdot 043
$$


The data fit both models very well: the two degrees of freedom accounted for by the mating preferences contribute most of the variation present in the data.

\section{LIKELIHOOD SURFAGES OF THE MODELS}

The likelihood surface of a model can be described in terms of levels of support relative to the maximum likelihood (Edwards, 1972). From a point where the estimates of the parameters give a log likelihood one unit below the maximum, the likelihood can be increased by $e \cong 2.718$ by changing the estimates to those of maximum likelihood. The likelihood surface can be represented by the contours of the levels of support-the contours at given units of log likelihood below the maximum. If a sample mean, $\bar{x}$, is normally distributed with standard error $\sigma / \sqrt{ } n$, then the 2-unit limits of support for estimates $\hat{\mu}$, of the population mean, $\mu$, occur at the points $\bar{x} \pm 2 \sigma / \sqrt{ } n$. These are approximately the 95 per cent confidence limits: in moving from the point $\hat{\mu}=\bar{x}+2 \sigma / \sqrt{ } n$ (or the point $\hat{\mu}=\bar{x}-2 \sigma / \sqrt{ } n$ ) to the point $\hat{\mu}=\bar{x}$, the likelihood is increased by the factor $e^{2}$.

For all models, we have calculated the support relative to the maximum likelihood of model $4 \mathrm{P}$, the model with the highest likelihood. For models 3 and 4 , the values of support were calculated over the whole range of values of

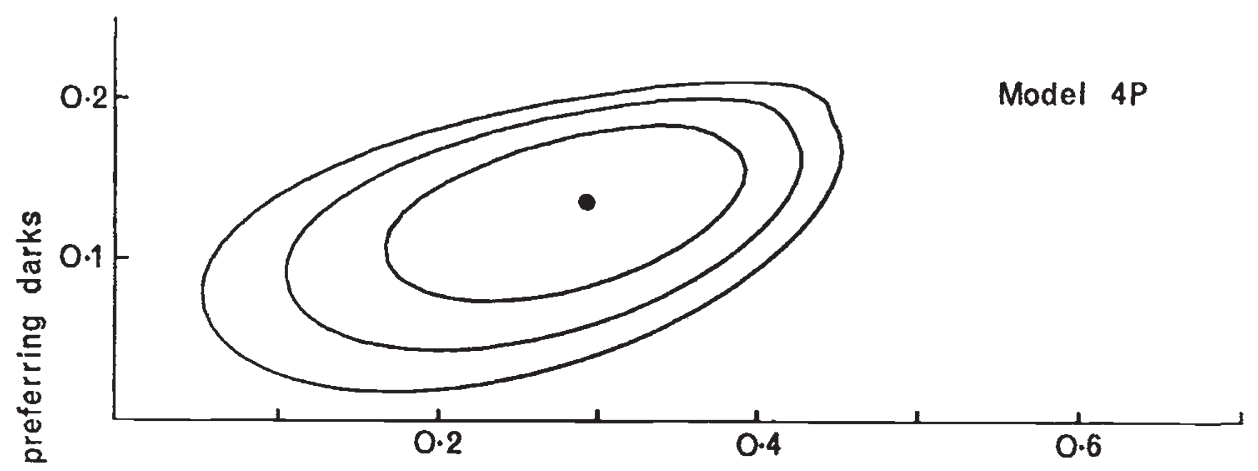
support limits relative to the maximum log likelihood of model $4 \mathrm{P}$, which has the highest likelihood of all the models. The point of maximum likelihood is shown by the small black circle. For model 3P, the point of maximum likelihood is also shown when there is assumed to be no female preference for dark males by themselves (i.e. when $\alpha=0$ ). This is the point of maximum likelihood of model IP. 
$\alpha$ and $\beta$. Thus for models 4 , we calculated the support for the 2500 points representing the combinations of values

$$
\begin{aligned}
& \alpha=0.0,0.01,0.02, \ldots, 0.49 \\
& \beta=0.0,0.01,0.02, \ldots, 0.49 .
\end{aligned}
$$

The contours of support at 1-, 2- and 3-units were then found by interpolation and drawn on the graph plotter of the IBM 370/165 Computer at Cambridge.

Figs 1, 2 and 3 show the support limits for models $3 P$ and $4 P, 3 R$ and $4 R$ and $3 \mathrm{~S}$ and $4 \mathrm{~S}$. The points of maximum likelihood are shown by the black circles. For models $3 \mathrm{P}$ and $4 \mathrm{P}$, the support limits are fairly wide: the likelihood surfaces rise to a higher point than that of the other models. However, the likelihoods drop away very sharply at the higher values of $\alpha$-the preference of females for darks alone. All the models show this feature. Model 3 becomes identical to model 1 when $\alpha=0$. The points where the support limits touch the line $\alpha=0$ are the support limits of the values of $\beta$. Thus for model $1 \mathrm{P}$, we have at maximum likelihood $\hat{\beta}=0.425$ with 2-unit support limits

$$
0 \cdot 193 \leqslant \beta \leqslant 0 \cdot 592
$$

corresponding roughly to 95 per cent confidence limits. Generally the parameter values are very unlikely to be outside the 3-unit limits of support. A normally distributed parameter will be within the inner, 1-unit limits

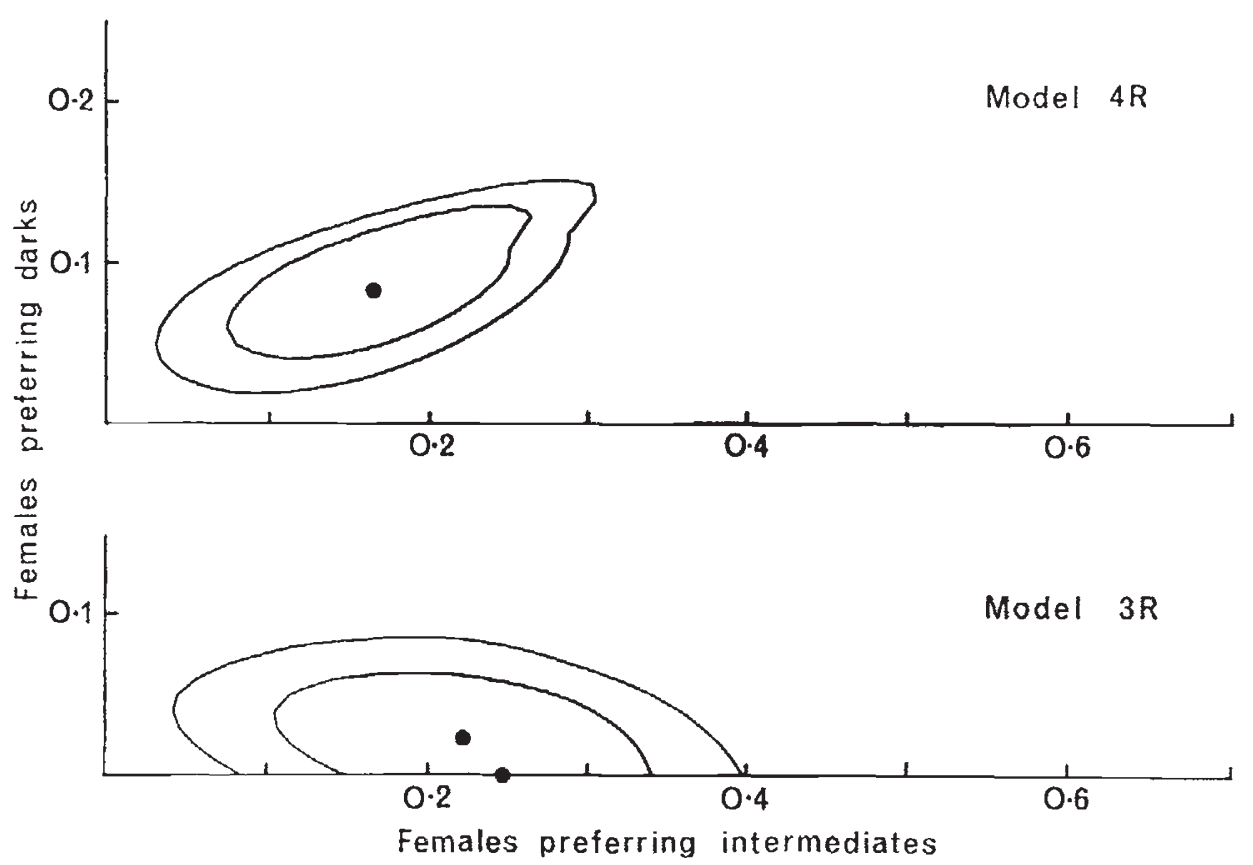

Fic. 2.-The log likelihood surfaces of models $3 R$ and $4 R$. Only the 2- and 3-unit support limits are shown since relative to model $4 \mathrm{P}$ the likelihoods of the $\mathrm{R}$ models do not reach the l-unit level of support. For model 3R, the point of maximum likelihood is also shown when $\alpha=0$ (model 1R). 


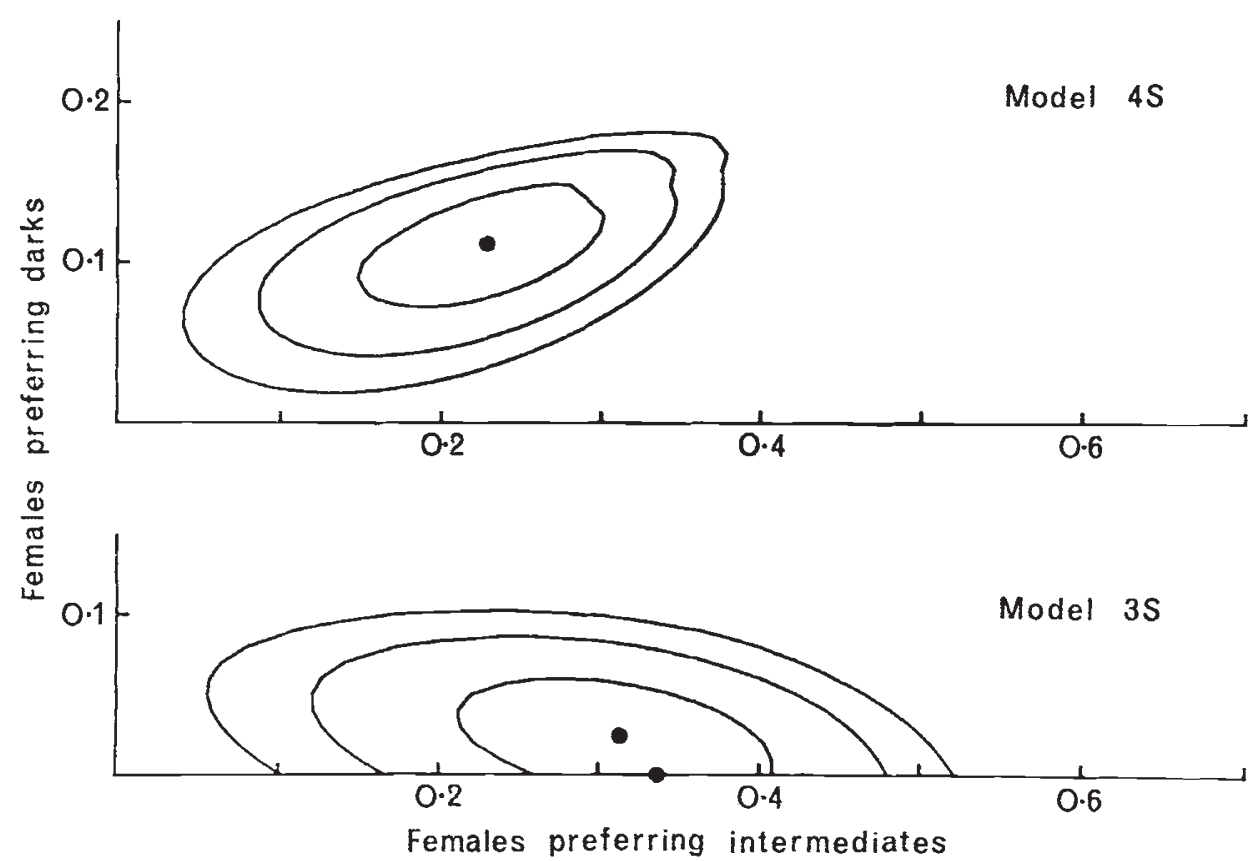

Fig. 3.- The log likelihood surfaces of models 3S and $4 \mathrm{~S}$ drawn with 1-, 2- and 3-unit support limits relative to model $4 \mathrm{P}$. For model $3 \mathrm{~S}$, the point of maximum likelihood is also shown when $\alpha=0$ (model $1 \mathrm{~S}$ ).

with a probability of roughly 84 per cent, and within the middle, 2-unit limits with a probability of roughly 95 per cent.

The increase of support from the $\mathrm{R}$ to the $\mathrm{P}$ models is about $1 \cdot 1$ units. Therefore the maximum log likelihood of the $\mathrm{R}$ models lies below the 1 -unit limits of the $\mathrm{P}$ models. Fig. 2 shows the support for the $\mathrm{R}$ models relative to the maximum log likelihood of model 4P. Only the 2- and 3-unit limits appear in this figure since the likelihood surface does not reach the 1-unit level.

\section{TEStS OF heterogeneity AND ANALysis of $\chi^{2}$}

There may be differences in the data between the two periods, 1948-62 and 1973-75, when the colony of Arctic Skuas was studied on Fair Isle. After fitting the parameters of the models, the residual heterogeneity in the data can then be analysed. This heterogeneity between the two periods may be caused by variation in the mating preferences, the frequencies of the phenotypes and the breeding times. To obtain reasonable expected numbers for the calculations of $\chi^{2}$, the data of the first and last 2 weeks of the breeding season have again been amalgamated. The two periods when the Fair Isle Arctic Skuas were studied are then each represented by a $3 \times 4$ contingency table. There are 24 classes for the calculation of $\chi^{2}$. Table 4 gives the two contingency tables. When the two contingency tables are added together, we obtain the overall proportions of birds breeding in each interval of the breeding season and the overall proportions of the phenotypes. These are also shown in table 4 . From these proportions, and the total 
TABLE 4

Conlingency tables for tests of heterogeneity and analysis of $\chi^{2}$

\begin{tabular}{|c|c|c|c|c|c|c|c|}
\hline \multirow{2}{*}{$\begin{array}{l}\text { Breeding dates in } \\
\text { specified intervals }\end{array}$} & \multicolumn{3}{|c|}{$\begin{array}{l}\text { Numbers observed } \\
\text { in period 1948-62 }\end{array}$} & \multicolumn{3}{|c|}{$\begin{array}{l}\text { Numbers obscrved } \\
\text { in period } 1973-75\end{array}$} & \multirow{2}{*}{$\begin{array}{l}\text { Proportion of all } \\
\text { birds breeding in } \\
\text { interval }\end{array}$} \\
\hline & Darks & Inters & Pales & Darks & Inters & Pales & \\
\hline 10-23 June & 9 & 26 & 4 & 2 & 9 & 1 & $p_{2}=51 / 241$ \\
\hline 24-30 June & 16 & 19 & 6 & 5 & 27 & 3 & $p_{2}=76 / 241$ \\
\hline 1-7 July & 10 & 24 & 6 & 5 & 9 & 7 & $p_{3}=61 / 241$ \\
\hline 8-21 July & 4 & 17 & 10 & 4 & 11 & 7 & $p_{4}=53 / 241$ \\
\hline $\begin{array}{l}\text { Totals of each } \\
\text { phenotype }\end{array}$ & 39 & 86 & 26 & 16 & 56 & 18 & \\
\hline Totals in each period & & 151 & & & 90 & & \\
\hline
\end{tabular}

Proportion of all darks: $p_{D}=55 / 241$

Proportion of all intermediates: $p_{I}=142 / 241$

Proportion of all pales: $p_{P}=44 / 241$

numbers of birds observed in each period, the expected numbers in each class can be calculated and hence an overall value of $\chi^{2}$. In calculating this $\chi^{2}$, the number of degrees of freedom have been reduced as follows:

(i) Three degrees of freedom for the three independent estimates of the overall proportions of birds in the four intervals of the breeding season;

(ii) Two degrees of freedom for the two independent estimates of the overall proportions of the three phenotypes;

(iii) Two degrees of freedom for the total number of birds observed in each of the periods 1948-62 and 1973-75.

Thus 17 degrees of freedom are left and we obtain

$$
\chi_{17}^{2}=32 \cdot 615 \text {. }
$$

By fitting the two parameters of the mating preferences, two more degrees of freedom are removed. Table 5 shows the effects of fitting the parameters of models $3 \mathrm{P}$ and $4 \mathrm{P}$, using the estimates shown in table 3 . Given the overall proportions of phenotypes and birds breeding in the intervals of the breeding season, the computer programmes for models $3 \mathrm{P}$ and $4 \mathrm{P}$ were used to calculate the expected frequencies and hence the expected numbers in each of the 24 classes. The values of $\chi^{2}$ shown in table 5 thus represent residual heterogeneity, part of which may be determined by variation in the mating preferences, the frequencies of the phenotypes or the breeding times.

TABLE 5

Effects of filting mating preferences to the data of males in the periods 1948-62 and 1973-75

\begin{tabular}{|c|c|c|c|}
\hline \multirow{2}{*}{$\begin{array}{l}\text { Model } \\
\text { fitted }\end{array}$} & \multicolumn{2}{|c|}{ Values of paramcters } & \multirow{2}{*}{$\begin{array}{l}\text { Residual value } \\
\text { of } \chi^{2} \text { after } \\
\text { fitting parameters }\end{array}$} \\
\hline & $\alpha$ & $\beta$ & \\
\hline $3 \mathrm{P}$ & 0.024 & 0.402 & 21.076 \\
\hline $4 \mathrm{P}$ & $0 \cdot 137$ & 0.292 & $20 \cdot 863$ \\
\hline
\end{tabular}

The expected numbers in the 24 classes of table 4 have been calculated using the overall proportions of the phenotypes and the overall proportions of birds breeding in the different intervals of the breeding season. The values of $\chi^{2}$ therefore have 15 degrees of freedom. 
Table 6 shows the differences in the breeding times and table 7 the differences in the proportions of the phenotypes. The value of $\chi^{2}$ for the

\section{TABLE 6}

Test of heterogeneity in breeding times in the periods 1948-62 and 1973-75

$\begin{array}{cccc}\begin{array}{c}\text { Breeding dates } \\ \text { in specified } \\ \text { intervals }\end{array} & \begin{array}{c}\text { Numbers } \\ \text { for } \\ 1948-62\end{array} & \begin{array}{c}\text { Numbers } \\ \text { for } \\ 1973-75\end{array} & \begin{array}{c}\text { Combined } \\ \text { totals }\end{array} \\ \text { 10-23 June } & 39 & 12 & 51 \\ \text { 24-30 June } & 41 & 35 & 76 \\ \text { 1-7 July } & 40 & 21 & 61 \\ \text { 8-21 July } & 31 & 22 & 53 \\ \text { Totals } & 151 & 90 & 241\end{array}$

There are 3 degrees of freedom and $\chi_{3}^{2}=7 \cdot 238$.

TABLE 7

Test of heterogeneity in proportions of phenotypes in the periods 1948-62 and 1973-75

$\begin{array}{lccc} & \begin{array}{c}\text { Numbers } \\ \text { for } \\ \multicolumn{1}{c}{\text { Phenotypes }}\end{array} & \begin{array}{c}\text { Numbers } \\ \text { for }\end{array} & \begin{array}{c}\text { Combined } \\ \text { totals }\end{array} \\ \text { Dark males } & 394-62 & 1973-75 & 55 \\ \text { Intermediate males } & 86 & 16 & 142 \\ \text { Pale males } & 26 & 56 & 44 \\ \text { Totals } & 151 & 90 & 241\end{array}$

These are 2 degrees of freedom and $\chi_{2}^{2}=2 \cdot 106$.

differences in breeding times is nearly significant with a probability of about 7 per cent. This does seem to be largely a chance effect, however: when the data are classified into different weekly intervals, the value of $\chi^{2}$ is reduced considerably. These components of heterogeneity are independent. They are components in the three-dimensional cortingency table (table 4). In

\section{TABle 8}

Analysis of $\chi^{2}$ when model $4 P$ is fitted to the data

\begin{tabular}{|c|c|c|}
\hline Component of variation & Value of $\chi^{2}$ & $\begin{array}{l}\text { Degrees of } \\
\text { freedom }\end{array}$ \\
\hline $\begin{array}{l}\text { Parameters } \alpha \text { and } \beta \text { of model } 4 \mathrm{P} \\
\text { Differences in breeding times }\end{array}$ & $11 \cdot 752 * * *$ & 2 \\
\hline between $1948-62$ and $1973-75$ & $7 \cdot 238 * *$ & 3 \\
\hline $\begin{array}{l}\text { Differences in proportions of } \\
\text { phenotypes between 1948-62 } \\
\text { and 1973-75 }\end{array}$ & & 2 \\
\hline Residual heterogeneity & $11 \cdot 519$ & 10 \\
\hline Total & $32 \cdot 615^{*}$ & 17 \\
\hline
\end{tabular}

the analysis of multidimensional contingency tables, values of $\chi^{2}$ are not exactly additive: they are additive asymptotically as the sample size increases; the analysis of $\chi^{2}$ is a good approximation. Table 8 gives the analysis of $\chi^{2}$ 
when model $4 \mathrm{P}$ is fitted to the data. A very similar analysis is obtained if model $3 \mathrm{P}$ is fitted: the residual heterogeneity is then inereased slightly $\left(\chi_{10}^{2}=11 \cdot 733\right)$ and the significance of the fitted parameters of the mating preferences is correspondingly reduced $\left(\chi_{2}^{2}=11 \cdot 538\right)$.

The analysis of $\chi^{2}$ shows that the data fit the models of the mating preferences very well. Both the fitting of the models and the analysis of variance shown in table 2 give about the same level of significance at $\mathrm{P} \cong$ 0.005 . There may be some heterogeneity in breeding times between the years when the Arctic Skuas were studied, but no significant heterogeneity remains after the removal of variations in breeding time and phenotypic frequencies.

\section{Discussion and conclusions}

The data for the period 1973-75 were not complete at the time of writing the earlier papers. For the period of 1948-62, O'Donald (1967a) found that model 4R had the highest likelihood. But between all models except $2 \mathrm{P}$ and $2 \mathrm{R}$, the differences in likelihood were very small. Models $2 \mathrm{P}$ and $2 \mathrm{R}$ were excluded at the 2-unit level of support. When the data of 1973-75 are included in the analysis, models $2 \mathrm{P}$ and $2 \mathrm{R}$ are excluded at almost 4 units of support. For the rest, the $\mathrm{R}$ models now appear to be supported much less than the P models, but the difference in support is not statistically significant.

The collection of further data on the breeding times of the Arctic Skua should discriminate between these models. At the same time, behavioural observations of the process of pair formation should also refute some of the models. For example, birds without previous breeding experience appear to congregate in "clubs" in particular parts of the colony. Most of the difference in breeding times is observed when males mate for the first time. If the females seleet their mates from the group of males in a club, the $\mathrm{P}$ or $\mathrm{R}$ models might represent the mechanism of pairing and mate selection, but not the $\mathbf{S}$ models: if the females arrive successively to mate and encounter different males at random, the $\mathbf{S}$ models might represent the mechanism of pairing. The observations on " clubs" thus suggests that the P or R models are the most appropriate to the present data. Further observations may discriminate between the $\mathrm{P}$ and $\mathrm{R}$ models: these models assume that the preferential and random matings take place within a group of males and females, the preferential matings either preceding or following the random matings.

Assortative mating occurs between intermediates on Fair Isle (O'Donald, Davis and Broad, 1974; Davis and O'Donald, 1976). The preference of intermcdiate females for intermediate males is very close to the overall preference for intermediates according to model $4 \mathrm{P}$. Davis and O'Donald estimated the assortative mating preference for intermediates from data of numbers of matings between different phenotypes. The maximum likelihood estimate of the assortative mating preference for intermediates was found to be $\beta=0.452$. Assuming this is a preference entirely of females for males, 45.2 per cent of intermediate females prefer intermediate males. In model 4P, 29.2 per cent of females prefer intermediate males. In the data on the assortative mating intermediates form 60.2 per cent of the birds. Thus the proportion of all females with preferences for intermediates is $0.602 \times 0.452=0.272$, or 27.2 per cent, which is very close to the estimate of the preference in model $4 \mathrm{P}$. The assortative mating of intermediates 
thus gives independent support to model 4 , in which a proportion of females have a specific preference for intermediates. Model 4 also has a slightly higher likelihood than model 3 when each of the corresponding $\mathrm{P}, \mathrm{R}$ and $\mathrm{S}$ models are compared.

We therefore conclude that model $4 \mathrm{P}$ is the best model to represent the mechanism of mate selection in the Arctic Skua: it has the highest likelihood and is supported by independent observations on breeding behaviour and assortative mating. According to this model, I4 per cent of the females prefer dark males and 29 per cent prefer intermediate males. These mating preferences are sufficient to maintain a stable polymorphism. O'Donald (1974) showed that the gene frequency of the allele for dark should reach stable equilibrium at a frequency

$$
p_{e}=\frac{\alpha+\frac{1}{2} \beta}{\alpha+\beta} .
$$

With the estimated values of $\alpha$ and $\beta$, we have

$$
p_{e}=0.66 \text {. }
$$

The actual gene frequency was 0.51 in 1975 . However, it has been shown that the pale phenotypes have an overall advantage because they are generally younger when they first breed (O'Donald, and Davis, 1976). The allele for pale may therefore be spreading through the population against the sexual selection for dark.

O'Donald (1976b) suggested that the $\mathrm{P}$ models would represent a mechanism of pairing in which the females have different thresholds of response to the male phenotypes. The female preferences might have evolved by the selection of a gene that lowers the threshold of the females' responses to the dark or intermediate males. Mating preferences should originally evolve only for genotypes that have a selective advantage: females mating with the advantageous males gain an advantage because their sons tend to have the favoured genotype. But once established, the mating preference itself adds to the advantage of the preferred male genotypes. This promotes what Fisher (1930) called a "runaway process". O'Donald (1967) showed that both the gene for the preferred male characteristic and the gene for the female preference would evolve together. This occurs because the preferred males, which increase in frequency as a result of selection, also tend to carry the mating preference gene. If the preferred genotypes later become disadvantageous as a result of a change in natural selection, the mating preferences will still maintain a polymorphism against the pressures of natural selection.

In the more northerly parts of its breeding range, Arctic Skuas are almost all pale. The Long-tailed and Pomarine Skuas, which both have a breeding range restricted to the Arctic, are also mainly pale. Thus, in the colder and harsher conditions of the Arctic, pale must have a general advantage over dark and intermediate. Perhaps in the earlier and warmer periods of the interglacial, intermediates and darks may have had the overall advantage: they must certainly have been advantageous in the more southerly parts of the range where they are still the most common phenotypes today. The female preferences might have evolved before the onset of cooler conditions and thus still provide a component of selection in favour of the darker phenotypes. 


\section{REFERENCES}

DAVIS, J. W. F, AND O'DONALD, P. 1976. Estimation of assortative mating preferences in the Arctic Skua. Heredity, 36, 235-244.

rDWARDs, A. W. F. 1972. Likelihood. The University Press, Cambridge.

Fisher, R. A. 1930. The Genetical Theory of Natural Selection. The Clarendon Prcss, Oxford. O'DONALD, P. 1967. A general model of sexual and natural selection. Heredity, 22, 499-518. O'DONALD, P. 1974. Polymorphisms maintained by sexual selection in monogamous species of birds. Heredity: $32,1-10$.

o'DonaI,D, P. 1976a. Mating preferences and their genetic cffects in models of sexual selection for colour phases of the Arctic Skua. Population Genetics and Ecology, cd. S. Karlin and E. Nevo, pp. 411-430. Academic Press, New York.

O'DONALD, P. 1976b. Mating preferences and sexual selection in the Arctic Skua. II. Bchavioural mechanisms of the mating preferences. Heredity, 39, 111-119

O'DONALD, P., AND DAvis, J. W. $\mathrm{F}$. 1976. A demographic analysis of the components of selection in a population of Arctic Skuas. Heredity, 36, 343-350.

O'DONALD, P., DAVIS, J. W. F., AND BROAD, R. A. 1974. Variation in assortative mating in two colonies of Arctic Skuas. Nature, 252, 700-701.

U'DONALD, P., WEDD, N. S., AND DAVIS, J. W. F. 1974. Mating preferences and sexual selection in the Arctic Skua. Heredily, 33, 1-16. 